\title{
Screening Performance and Costs of Different Strategies in Prenatal Screening for Trisomy 21
}

\author{
Testgüte und Kosten verschiedener Ansätze \\ im pränatalen Screening auf Trisomie 21
}

Authors

Affiliations
K. O. Kagan ${ }^{1}$, M. Schmid ${ }^{2}$, M. Hoopmann ${ }^{1}$, P. Wagner ${ }^{1}$, H. Abele ${ }^{1}$

${ }^{1}$ Department of Obstetrics and Gynecology, University of Tübingen, Tübingen

${ }^{2}$ Department of Obstetrics and Gynecology, University of Vienna, Vienna, Austria

\author{
Key words \\ - first trimester screening \\ cell-free fetal DNA \\ - trisomy \\ screening \\ Schlüsselwörter \\ - Ersttrimester-Screenings \\ - zellfreie fetale DNA \\ - Trisomie \\ - Screening
}

Deutschsprachige

Zusatzinformationen online abrufbar unter: www.thieme-connect.de/ ejournals/toc/gebfra

\section{received 22.12.2014 \\ revised 8.2.2015 \\ accepted 10.2.2015}

Bibliography

DOI http://dx.doi.org/

10.1055/s-0035-1545885

Geburtsh Frauenheilk 2015; 75:

244-250 @ Georg Thieme

Verlag KG Stuttgart · New York. ISSN 0016-5751

\section{Correspondence}

Dr. Karl Oliver Kagan, MD, PhD

University of Tübingen

Department of Obstetrics

and Gynecology

Calwerstraße 7

72076 Tübingen

KOKagan@gmx.de

\section{Abstract \\ $\nabla$}

Objective: Cell-free fetal DNA (cffDNA) testing has opened new options in prenatal screening for trisomy 21. Due to the higher costs of cffDNA testing there is an ongoing debate on how to combine different screening strategies.

Methods: For this study, a model-based approach was used to evaluate all births in Germany in 2012 together with the percentage of euploid and trisomic pregnancies. Detection rates (DR), false positive rates (FPR), the costs of different screening strategies for trisomy 21 and combinations of these strategies were compared. The number of fetuses with trisomy 21 at $12+0$ weeks of gestation was estimated based on maternal age distribution. We examined the screening performance of a screening strategy based on maternal age, first trimester screening (FTS) and cffDNA testing as well as the combinations "maternal age and cffDNA" and "FTS and cffDNA".

Results: In 2012673544 children were born. Median maternal age at delivery was 30.2 years (25th-75th quartile: 27.0-34.0). Based on maternal age distribution the expected number of fetuses with trisomy 21 at 12 weeks' gestation was 1788. Our study population therefore consisted of 675332 pregnancies. Screening based only on maternal age or FTS or cffDNA resulted in detection rates of $63.3 \%, 92.2 \%$ and $99.0 \%$ and false positive rates of $21.8 \%, 8.0 \%$ and $0.1 \%$, respectively. When maternal age was combined with cffDNA, cffDNA testing was only offered to women over a certain age; if a cut-off of 30 years was used, this resulted in a DR of $85.2 \%$ and a FPR of $1.7 \%$. If primary screening consisted of FTS with cffDNA testing only done when the risk was between $1: 10$ and $1: 1000$, the detection rate was $96.7 \%$ and the false positive rate was $1.2 \%$. Conclusion: In this model-based study we showed that prenatal screening for trisomy 21 can be improved even more by combining FTS

\section{Zusammenfassung \\ $\nabla$}

Zielsetzung: Durch die Einführung der zellfreien fetalen DNA (cffDNA)-Analyse eröffnen sich derzeit neue Möglichkeiten im pränatalen Screening auf Trisomie 21. Der höheren Testgüte stehen jedoch höhere Kosten gegenüber, sodass durch eine Kombination der verschiedenen Screening-Verfahren die Vorteile der verschiedenen Ansätze nutzbar gemacht werden sollen. In dieser Arbeit sollen die Testgüte und die Kosten der verschiedenen Screening-Ansätze untersucht werden.

Methoden: In dieser Arbeit wurden in einer Modellrechnung die Detektions- und Falschpositivrate (DR und FPR) sowie die Kosten unterschiedlicher Ansätze im Screening auf Trisomie 21 und deren Kombinationen verglichen. Das Modell basierte auf den Geburten in Deutschland 2012, die den euploiden Anteil repräsentierten. Der Anteil der Feten mit Trisomie 21 bei $12+0$ SSW wurde auf der Basis der Altersstruktur des mütterlichen Alters und deren Häufigkeit in der Geburtenkohorte 2012 geschätzt. Berechnet wurde die Testgüte für das Screening anhand des mütterlichen Alters, des Ersttrimester-Screenings, der cffDNAAnalyse sowie den Kombinationen aus mütterlichem Alter und cffDNA und ETS und cffDNA.

Ergebnisse: 2012 wurden 673544 Kinder geboren. Das mediane Alter der Mütter bei Entbindung lag bei 30,2 (25.-75. Quartil 27,0-34,0) Jahren. Entsprechend der mütterlichen Altersstruktur sind daher in der $12+0$ SSW 1788 Feten mit Trisomie $21 \mathrm{zu}$ erwarten. In Summe beinhaltet die Studienpopulation somit 675332 Schwangerschaften. Das Screening anhand des mütterlichen Alters und des ETS resultiert in einer DR von 63,3 und $92,2 \%$ bei einer FPR von 21,8 und $8,0 \%$. Für die cffDNA-Analyse werden als DR und FPR 99,0 und $0,1 \%$ angenommen. Bei der Kombination des mütterlichen Alters und der cffDNA-Analyse wird ab einem mütterlichen Alter eine cffDNA-Analyse durchgeführt. Bei einem Schwellenwert von 30 
and cffDNA. Further studies are necessary to examine whether these results can be reproduced in reality.
Jahren liegen die DR und FPR bei 85,2 und 1,7\%. Bei Verwendung des ETS und im Intermediär-Risikokollektiv cffDNA sind bei Schwellenwerten von 1:10 und 1:1000 eine DR und eine FPR von 96,7 und $1,2 \%$ zu erwarten.

Schlussfolgerung: In dieser Modellrechnung konnte gezeigt werden, dass vor allem durch die Kombination aus ETS und cffDNA-Analyse das Screening auf Trisomie 21 optimiert werden kann. Nachfolgende Studien sollten untersuchen, ob die positiven Aspekte dieses Kombinationsansatzes auch in der Realität zu beobachten sind.

\section{Introduction}

\section{$\nabla$}

Prenatal screening for trisomy 21 has continuously improved in the past decades. Combined first trimester screening (FTS) has played an important role in this, and in many countries it is now a standard part of prenatal care. Over the past few years it has been expanded by the addition of risk stratification for numerous complications of pregnancy $[1,2]$.

The introduction of FTS has resulted in a significant decrease in the rates of invasive diagnostic procedures (chorionic villus sampling [CVS] and amniocentesis), despite the continued increase in median maternal age. The impact of FTS was particularly pronounced in England and Denmark. Morgan et al. showed that after changes in screening policy, the overall screen-positive rate in England, which was previously based on biochemical screening done in the second trimester, decreased from 6 to 3.1\% [3]. Similarly, Ekkelund et al. reported that after the nation-wide introduction of FTS in Denmark, the false positive rate dropped to $3.3 \%$ [4]. By comparison, outdated screening programs based only on maternal age were found to have a false positive rate of $20 \%$ when a cut-off of 35 years was used.

The introduction of cell-free fetal DNA (cffDNA) testing has offered a new way of screening for trisomy $21[5,6]$. The reported detection rate and the false positive rate are 99 and $0.1 \%$, respectively [7]; this approach involves fewer potential sources of error for medical practitioners and, with the exception of being qualified to provide information and consultation in accordance with the German Gene Diagnostics Law, no additional training is needed. The drawbacks of cffDNA are that it focuses only on the most common chromosomal disorders; that the test results of some pregnancies will be inconclusive because of insufficient cffDNA in maternal blood; that dichorionic multiple pregnancies, particularly vanishing-twin syndrome, reduce the test quality; and finally, that this form of screening is considerably more expensive than other methods.

The question is therefore what would be the best combination of different screening methods for Germany which would not relinquish the benefits of previous strategies but would instead improve the quality of screening. The economic impact of introducing an updated screening algorithm must also be taken into account.

\section{Methods}

$\nabla$

This study used a model-based calculation to compare detection rates, false positive rates and the costs of different screening methods for trisomy 21 as well as outcomes for combinations of these methods. For the model a study population was defined consisting of euploid and trisomy 21 pregnancies. The published data on screening performance for the different screening strategies was used to determine detection rates and false positive rates for the study population.

\section{Study population}

The study population consisted of all births recorded in Germany in 2012 together with maternal age [8]. It was assumed that all pregnancies were euploid pregnancies. To estimate the number of fetuses with trisomy 21 in week $12+$ of gestation, the number of expected pregnancies with trisomy 21 in week $12+0$ of gestation was compiled from the sum calculated for each maternal age between the ages of 15 and 50, according to the maternal age distribution for the birth cohort of 2012 [8-10].

The number of fetuses with trisomy 21 delivered at term was calculated for every maternal age by multiplying the maternal age risk by the number of live term births. Because of the increased rate of miscarriages for fetuses with trisomy 21 , the expected number of fetuses with trisomy 21 born at term was multiplied by an adjustment factor to calculate the probable number of fetuses with trisomy 21 at $12+0$ weeks of gestation. The total number of expected fetuses with trisomy 21 in week $12+0$ of gestation was calculated by adding up the number of cases calculated for each maternal age.

The risk of trisomy 21 for a child delivered at term is:

Risk $=0.000627+\mathrm{e}^{-16.2395+0.286 \times(\text { mat. age }-0.5) \times 1.5}$

The adjustment factor for $12+0$ week of gestation is: $\operatorname{adj}=10^{0.9425-1.023 \times \text { LOG }_{10}(12)+0.2718 \times \text { LOG }_{10}(12) \times \text { LOG }_{10}(12)}$

and

Risk $_{12}$ SSW $=$ Risk $\times$ adj

Test quality and cost of individual screening methods Test quality of screening based on maternal age was calculated based on age distribution in the study. A pregnancy was considered screen-positive when the maternal age was above a defined cut-off.

Assessment of screening using cffDNA was based on a detection rate and a false positive rate of 99 and $0.1 \%$ [7]. Abnormal cffDNA results were considered screen-positive. If the result of cffDNA testing was inconclusive, which was expected for $3 \%$ of tests, the pregnancy was also categorized as screen-positive. It was assumed that the incidence of inconclusive tests was similarly distributed for the euploid and the trisomy 21 groups [5].

For combined FTS it was assumed that the distribution of risks in the study population corresponded to that of the reference population ( Table 1) [1]. If the risk was above a specific cut-off, the pregnancy was defined as screen-positive.

When a combination of screening methods was used, primary screening was done based either on maternal age or on FTS. A second screening using cffDNA was then carried out for the sub- 


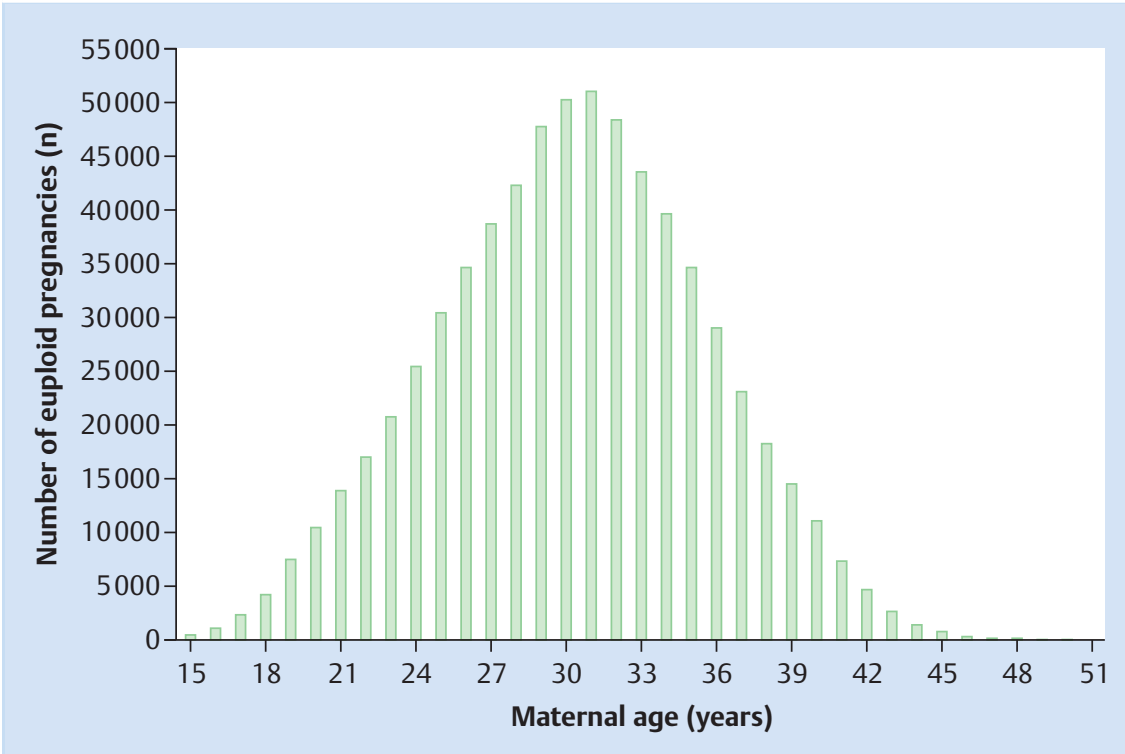

Fig. 1 Maternal age distribution at delivery of euploid children in Germany in 2012.

group defined as at risk in the primary screening. The test quality of the individual screening methods has been described above. It was posited that all screen-positive pregnancies would be investigated further using invasive diagnostics, and that the detection rate and false positive rate of invasive testing methods was 100 and $0 \%$, respectively.

The costs of FTS and of invasive diagnostic testing were estimated as $€ 150$ and $€ 1000$, respectively. Screening based on maternal age incurred no costs, and the cost of cffDNA testing was estimated as $€ 500$. In individual calculations, the cost of cffDNA testing was also calculated based on an estimated cost of $€ 250$.

\section{Results}

According to data from the German Federal Office of Statistics, 673544 children were born in 2012. Mean maternal age at delivery was 30.2 years (25th-75th quartile: 27.0-34.0) (○ Fig.1). Based on maternal age distribution, it was estimated that 1333 children with trisomy 21 would be born at term and the expected number of fetuses with trisomy 21 in week $12+0$ of gestation would be 1788 ( Fig. 2). The study population therefore consisted of 675332 pregnancies.

\section{Screening based on maternal age}

- Table 2 shows the detection rate, false positive rate and cost of screening for trisomy 21 based on maternal age using different cut-offs. The most commonly used cut-off of 35 years had a detection rate of $63.3 \%$ and a false positive rate of $21.8 \%$. The cost of such a screening strategy, which would be limited to the costs of invasive diagnostic procedures, was calculated as $€ 148267000$ or $€ 219.55$ per pregnancy.

\section{Screening based on FTS}

When screening for trisomy 21 was done using FTS and a cut-off of $1: 250,92.2 \%$ of cases with trisomy 21 were detected; the false positive rate was $8.0 \%$. For this cut-off, the costs were calculated as $€ 156832800$ or $€ 232.23$ per pregnancy. $\bullet$ Table 3 summarizes the results when other cut-offs are used.
Table 1 Risk distribution in combined FTS for euploid pregnancy and fetuses with trisomy 21.

\begin{tabular}{|lcc|}
\hline Risk & Euploid pregnancy & Trisomy 21 \\
$\geq 1: 10$ & $0.6 \%$ & $69.1 \%$ \\
\hline $1: 11-1: 50$ & $1.6 \%$ & $15.2 \%$ \\
\hline $1: 51-1: 100$ & $1.7 \%$ & $4.1 \%$ \\
\hline $1: 100-1: 250$ & $4.1 \%$ & $3.8 \%$ \\
\hline $1: 251-1: 1000$ & $13.1 \%$ & $4.8 \%$ \\
\hline $1: 1001-1: 5000$ & $29.6 \%$ & $2.5 \%$ \\
\hline$\leq 1: 5001$ & $49.4 \%$ & $0.5 \%$ \\
\hline Total & $\mathbf{1 0 0} \%$ & $\mathbf{1 0 0} \%$ \\
\hline
\end{tabular}

\section{Screening based on cffDNA}

When screening was done using cffDNA, the detection rate and false positive rate were 99 and $0.1 \%$, respectively. If a $3 \%$ fail rate requiring subsequent investigation with invasive diagnostics was postulated for the test, the total false positive rate was $3.1 \%$ $(\mathrm{n}=20859)$ while the detection rate remained the same at $99.0 \%(n=1770)$. The cost of such a screening strategy was calculated as $€ 360295000$ or $€ 533.51$ per pregnancy if the estimated cost of cffDNA testing was set at $€ 500$; the cost of the same screening strategy was $€ 191462000$ or $€ 283.51$ per pregnancy if the cost of cffDNA testing was reduced to $€ 250$ (675332 $\times$ $€ 500$ or $€ 250$ for cffDNA plus $€ 1000 \times 22629$ for invasive diagnostics).

\section{Screening based on maternal age and cffDNA}

Primary screening was based on maternal age. If the result was higher than a defined cut-off, a second screening was done using cffDNA. If the results were abnormal or inconclusive, the pregnancy was considered screen-positive and was investigated using invasive procedures.

If the cut-off was 30 years, $86.0 \%(n=1538)$ of fetuses with trisomy 21 and $56.1 \%(n=378181)$ of euploid pregnancies were investigated further using cffDNA ( $\bullet$ Table 2 ). The overall detection rate was $85.2 \%$ and the false positive rate was $1.7 \%$. The cost of this approach was $€ 203094500$ or $€ 300.73$ per pregnancy if the cost per cffDNA test was $€ 500$; overall costs were $€ 108164750$ or 


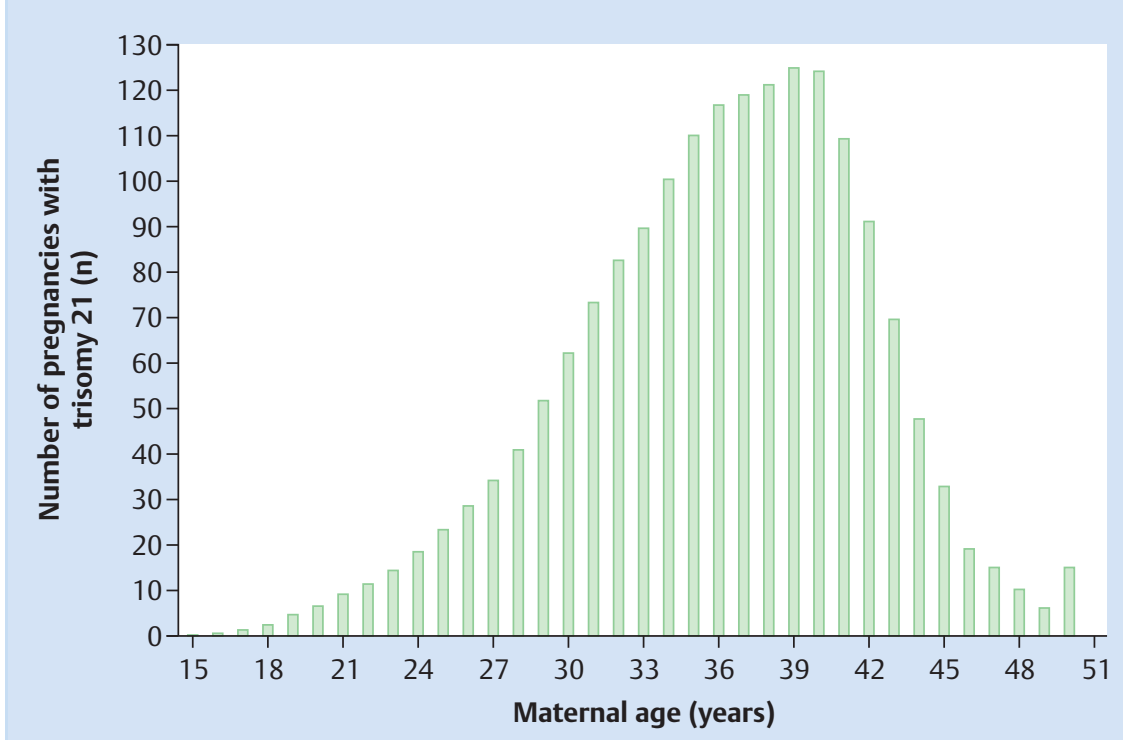

Fig. 2 Estimated maternal age distribution at delivery of children with trisomy 21 in Germany in 2012.

Table 2 Test quality and cost of screening for trisomy 21 based on maternal age.

\begin{tabular}{|c|c|c|c|c|c|}
\hline \multirow[t]{3}{*}{ Cut-off (years) } & \multirow{2}{*}{\multicolumn{2}{|c|}{$\begin{array}{l}\text { Detection rate } \\
n=1788\end{array}$}} & \multirow{2}{*}{\multicolumn{2}{|c|}{$\begin{array}{l}\text { False positive rate } \\
n=673544\end{array}$}} & \multirow[t]{3}{*}{ Cost (€) } \\
\hline & & & & & \\
\hline & $\mathbf{N}$ & $\%$ & N & $\%$ & \\
\hline 25 & 1716 & 96.0 & 570683 & 84.7 & 572399000 \\
\hline 30 & 1538 & 86.0 & 378181 & 56.1 & 379719000 \\
\hline 35 & 1131 & 63.3 & 147136 & 21.8 & 148267000 \\
\hline 40 & 541 & 30.3 & 28455 & 4.2 & 28996000 \\
\hline
\end{tabular}

Costs are calculated based on screening for age plus invasive diagnostic procedures:

screening for maternal age: 675332 pregnancies $x € 0$ plus

invasive diagnostics [number of screen-positive cases] $\times € 1000$

Table 3 Test quality and cost of screening for trisomy 21 using FTS.

\begin{tabular}{llllll} 
Cut-off (risk) & $\begin{array}{l}\text { Detection rate } \\
\mathbf{n = 1 7 8 8}\end{array}$ & \multicolumn{2}{l}{ False positive rate } \\
& $\mathbf{N}=\mathbf{6 7 3 5 4 4}$ & Cost (€) \\
& $\mathbf{N}$ & $\mathbf{\%}$ & $\mathbf{N}$ & \% & \\
$1: 50$ & 1507 & 84.3 & 14818 & 2.2 & 117624800 \\
\hline $1: 100$ & 1581 & 88.4 & 26268 & 3.9 & 129148800 \\
\hline $1: 250$ & 1649 & 92.2 & 53884 & 8.0 & 156832800 \\
\hline $1: 1000$ & 1779 & 99.5 & 341487 & 50.7 & 444565800 \\
\hline
\end{tabular}

Costs are based on the use of FTS plus invasive procedures:

FTS: 675332 pregnancies $\times € 150$ plus

invasive diagnostics [number of screen-positive cases] $\times € 1000$

$€ 160.17$ per pregnancy if the cost of the cffDNA test was $€ 250$. - Table 4 shows the test quality for other cut-off values.

\section{Screening based on FTS and cffDNA}

In this approach primary screening consisted of FTS with two threshold values used to define high-risk and low-risk groups. Additional testing consisting of cffDNA was done in the intermediate-risk group. Patients classified as high risk after FTS and with abnormal or inconclusive cffDNA test results were considered screen-positive and investigated further using invasive diagnostic procedures.
The frequency distribution for the respective risk classes is shown in Table 5 . When the threshold values $1: 10$ and $1: 1000$ were used, then $0.6,20.4$ and $79.0 \%$ of euploid pregnancies were classified respectively as high risk, intermediate risk or low risk. The corresponding distribution for fetuses with trisomy 21 was $69.1,27.9$ and $3.0 \%$, respectively. If these threshold values were used, the overall detection rate was $96.7 \%(n=1729)$ and the false positive rate was $1.2 \%(n=8296)$. Total costs were $€ 180275800$ and $€ 266.94$ per pregnancy or $€ 145800300$ and $€ 215.89$ per pregnancy, depending on whether the cost of cffDNA was set at $€ 500$ or at $€ 250$. 0 Table 6 shows the test quality and costs for the different threshold values. 
Table 4 Test quality and cost of screening based on maternal age followed by cffDNA when a defined cut-off is exceeded.

\begin{tabular}{|c|c|c|c|c|c|}
\hline \multirow[t]{3}{*}{ Cut-off (risk) } & \multirow{2}{*}{\multicolumn{2}{|c|}{$\begin{array}{l}\text { Detection rate } \\
n=1788\end{array}$}} & \multirow{2}{*}{\multicolumn{2}{|c|}{$\begin{array}{l}\text { False positive rate } \\
n=673544\end{array}$}} & \multirow[t]{3}{*}{ Cost $(€)$} \\
\hline & & & & & \\
\hline & N & $\%$ & $N$ & $\%$ & \\
\hline 25 & 1699 & 95.0 & 17674 & 2.6 & 305572500 \\
\hline 30 & 1523 & 85.2 & 11712 & 1.7 & 203094500 \\
\hline 35 & 1120 & 62.6 & 4557 & 0.7 & 79810500 \\
\hline 40 & 536 & 30.0 & 882 & 0.1 & 15916000 \\
\hline
\end{tabular}

Costs were calculated based on screening by maternal age followed by cffDNA plus invasive diagnostics:

screening by maternal age: 675332 pregnancies $\times € 0$ plus

cffDNA [pregnancies of women above a specific maternal age] $\times € 500$ plus

invasive diagnostics [screen-positive cases] $\times € 1000$

Table 5 Distribution of euploid and trisomy 21 pregnancies classified as high/intermediate or low risk after FTS.

\begin{tabular}{|c|c|c|c|c|c|c|c|}
\hline \multirow{3}{*}{\multicolumn{2}{|c|}{$\begin{array}{l}\text { Frequency distribution for euploid } \\
\text { pregnancies or trisomy } 21 \text { in FTS (\%) }\end{array}$}} & \multicolumn{6}{|c|}{ Threshold value used to defined the high-risk population } \\
\hline & & \multicolumn{2}{|l|}{$1: 10$} & \multicolumn{2}{|l|}{$1: 50$} & \multicolumn{2}{|l|}{$1: 100$} \\
\hline & & Trisomy 21 & Euploid & Trisomy 21 & Euploid & Trisomy 21 & Euploid \\
\hline \multirow{6}{*}{$\begin{array}{l}\text { Threshold value used to } \\
\text { define the low-risk group }\end{array}$} & \multirow[t]{3}{*}{$1: 1000$} & $69.1 /$ & 0.61 & 84.31 & 2.21 & 88.41 & $3.9 /$ \\
\hline & & $27.9 /$ & $20.4 \mid$ & $12.7 \mid$ & $18.8 /$ & $8.6 /$ & $17.1 /$ \\
\hline & & 3.0 & 79.0 & 3.0 & 79.0 & 3.0 & 79.0 \\
\hline & \multirow[t]{3}{*}{$1: 5000$} & $69.1 /$ & 0.61 & 84.31 & 2.21 & $88.4 \mid$ & $3.9 /$ \\
\hline & & $30.4 \mid$ & $50.0 /$ & 15.21 & $48.4 \mid$ & $11.1 /$ & $46.7 \mid$ \\
\hline & & 0.5 & 49.4 & 0.5 & 49.4 & 0.5 & 49.4 \\
\hline
\end{tabular}

Table 6 Test quality and cost of screening for trisomy 21 using FTS followed by cffDNA in the intermediate-risk group.

\begin{tabular}{|c|c|c|c|c|}
\hline \multirow{2}{*}{$\begin{array}{l}\text { False positive rate }(n, \%) \\
\text { Detection rate }(n, \%)\end{array}$} & & \multicolumn{3}{|c|}{ Threshold value used to define the high risk group } \\
\hline & & & & \\
\hline \multicolumn{5}{|l|}{ Cost $(€)$} \\
\hline & & $1: 10$ & $1: 50$ & $1: 100$ \\
\hline \multirow{6}{*}{$\begin{array}{l}\text { Threshold value used to } \\
\text { define the low-risk group }\end{array}$} & $1: 1000$ & $8296(1.2)$ & $18740(2.8)$ & $29835(4.4)$ \\
\hline & & $1729(96.7)$ & 1732 (96.9) & 1733 (96.9) \\
\hline & & 180275800 & 185198300 & 190532800 \\
\hline & $1: 5000$ & $14471(2.1)$ & $24914(3.7)$ & $36009(5.3)$ \\
\hline & & $1773(99.2)$ & $1776(99.3)$ & $1777(99.4)$ \\
\hline & & 286201800 & 291123300 & 296457300 \\
\hline
\end{tabular}

Costs are calculated based on FTS, cffDNA and invasive diagnostics:

FTS: 675332 pregnancies $x € 150$ plus

cffDNA [number of pregnancies in the intermediate-risk group] $\times € 500$ plus

invasive diagnostics [number of screen-positive cases] $\times € 1000$

\section{Discussion}

$\nabla$

This study used a model-based approach to show that use of cffDNA for primary screening or a combination of cffDNA with other screening methods could increase the detection rates for trisomy 21 to over $95 \%$ use and reduce the false positive rate to under $3 \%$. If the focus is on only test quality, then a combination of FTS and cffDNA testing was the most effective, as the detection rate with this combination was $96.7 \%$ and the false positive rate was $1.2 \%$. It was also more cost efficient than primary screening using cffDNA alone, as the false positive rate for the latter approach was $3.1 \%$ due to inconclusive cffDNA test results. A combination of screening based on maternal age and cffDNA testing did not achieve a similarly high test quality. If the objective is to achieve a detection rate of more than $95 \%$, then cffDNA would have to be made available to test pregnant women with a maternal age of 25 and above. This would mean that an additional cffDNA test would need to be carried out in $85 \%$ of the study population which would almost double the cost of screening compared to FTS or standard screening strategies based on maternal age.

If the focus is mainly on costs, then primary screening using cffDNA was the most expensive option with an average cost of around $€ 530$ per pregnancy if the cost per cffDNA test was $€ 500$. Combining cffDNA with FTS at threshold values of $1: 10$ and $1: 1000$ could reduce the cost by around half; the detection rate for this combination was over $96 \%$.

A further relevant reduction in costs could be achieved if the cost of cffDNA were to drop to around $€ 250$ per test. The cost of a combined strategy using FTS and cffDNA would then be around 
$€ 215$; primary screening based on cffDNA would then cost $€ 280$ per pregnancy.

In addition to the actual cost of the cffDNA test, the percentage of inconclusive test results is crucially important for the overall cost, as inconclusive test results will generally be followed by invasive diagnostic procedures which can be up to four times more expensive than cffDNA testing. The false positive rate together with the number of inconclusive test results means that the rate of invasive investigations is more than $3 \%$, which reduces the expected benefits of cffDNA again. However, taking repeat blood samples and re-analysis of samples can reduce the failure rate to around $1-2 \%$, which would result in a further significant reduction in overall costs [11].

Our results were comparable to those reported in other previous studies. Cuckle et al. also used a model-based approach to estimate the costs of different screening strategies (FTS, cffDNA and a combination of both methods) [12]. They based their model on an estimated cost of $\$ 150$ for FTS and $\$ 1000$ for invasive diagnostic procedures. Calculations were then done using different unit costs for cffDNA testing ( $\$ 500, \$ 1000, \$ 1500$ and $\$ 2000$ ). They concluded that the lion's share of screening costs for trisomy 21 would consist of the cost of cffDNA testing, and that cffDNA would only become interesting for public health purchasers if the cost of testing could be significantly reduced. Until that happens, the authors recommended using a 2-stage approach consisting of FTS followed by cffDNA testing in a subpopulation.

Morris et al. used a similar approach to investigate the cost of FTS, cffDNA, combinations of both methods and invasive diagnostics in a model-based calculation for 10000 patients. In contrast to the 2-stage model we used in our study where cffDNA testing was proposed for the intermediate-risk group, the authors assumed that cffDNA would be used in groups with an FTS risk of $1: 150$ and above. They did not define a high-risk group for which direct invasive diagnostics would be recommended. They concluded - just as Cuckle et al. did - that the use of cffDNA would become interesting for public healthcare systems if there were a further decline in the price of the test, as increased cffDNA testing would reduce the number of invasive diagnostic procedures required. Up until that point they also recommended using a 2stage strategy [13].

Beulen et al. discussed whether cffDNA testing could become the standard method for screening high-risk populations and whether it should become part of the overall screening strategy for trisomy 21 in the Netherlands and concluded that in view of the current cost structure, cffDNA was only suitable as an optional secondary screening test [14].

Song et al. used a model-based approach to compare FTS with integrated screening and cffDNA in a high-risk population previously identified using other screening tests and to test women aged 35 years and above. The authors concluded that the improved test quality of cffDNA meant that it was preferable to the other forms of screening [15].

Our study was based on specific assumptions which must be taken into consideration:

- Around $10 \%$ of patients in Germany have private healthcare. Higher payments for medical costs are expected in this patient cohort.

- The model-based calculation assumed that all pregnant women would avail themselves of the opportunity to screen for trisomies. In fact, some pregnant women reject all forms of genetic screening during pregnancy. However there is currently no robust study data on the percentage of women rejecting ge- netic screening. In principle, it must be assumed that the uptake rate for cffDNA testing will be higher than for FTS or screening based on maternal age. This is due to the simplicity of the test (taking a blood sample), the excellent test quality and the easier interpretation of test results.

- The combination of FTS and cffDNA can only achieve the calculated test quality if primary screening - in other words, FTS has a detection rate of $90 \%$ and a false positive rate of $5 \%$ as described in previous studies. In a study by Lüthgens et al. in more than 38000 pregnancies, it was found that the detection rate in Germany was around 10\% lower than expected, which would mean that the overall test quality falls short of expectations [16].

- This study only considered the actual costs of screening which were calculated based on the sum of the screening costs plus the costs of invasive diagnostic procedures. To comprehensively assess the costs involved, it would also be necessary to include the additional costs of early or late termination of pregnancy, additional direct medical costs incurred over the course of a lifetime of a person with trisomy 21 , and the indirect costs arising in consequence of the potentially reduced capacity to work of one of the parents due to the higher level of care required by a child with trisomy 21 . Such an evaluation would be equivalent to weighing up the value of a life, and ethical and moral reasons prevented this line of investigation from being pursued further.

In principle, it could be asked why only the intermediate-risk group should benefit from cffDNA testing when FTS is combined with cffDNA testing and why it should not be done in all pregnancies above a certain threshold value. It is therefore important to emphasize that trisomy 21 only constitutes around $50 \%$ of possible chromosomal defects and that other chromosomal disorders are often also associated with low PAPP-A levels and high nuchal translucency. But these markers are also indications of a higher risk for trisomy 21 [17]. Given the potential for other chromosomal abnormalities which may not be recognized using cffDNA, invasive diagnostic procedures should be carried out in high-risk populations in preference to cffDNA testing. In a study involving FTS performed in more than 21000 FTS pregnancies it was found that out of 212 fetuses with chromosomal abnormalities 23 (10.9\%) had chromosomal abnormalities which could not have been detected using cffDNA. Around 70\% of these cases had an FTS risk of $1: 50$ [18]. In a high-risk group with an FTS risk of more than $1: 10$, which corresponds to around $1 \%$ of the population, around half will have trisomy 21 ; for reasons of cost-efficiency and time constraints direct karyotyping should be done in this group [1].

\section{Conclusion \\ $\nabla$}

In this model-based study we showed that a combination of FTS and cffDNA testing could optimize screening for chromosomal disorders and reduce costs to reasonable levels compared to primary screening done using only cffDNA. Further studies will be necessary to show whether the positive findings of this combined approach can be reproduced in reality.

Finally, it should be noted that state-of-the-art prenatal care in the first trimester should not only focus on the detection of fetal aneuploidies but must also include screening for other fetal abnormalities and serious complications of pregnancy, some of them treatable, as part of individualized optimal care [2]. 


\section{Acknowledgement}

$\nabla$

This study was carried out with the support of the Working Group for Materno-fetal Medicine.

\section{Conflict of Interest}

$\nabla$

Maximilian Schmid is a consultant to Ariosa Diagnostics, manufacturer of the Harmony ${ }^{\circledR}$ prenatal test.

\section{References}

1 Kagan KO, Wright D, Baker A et al. Screening for trisomy 21 by maternal age, fetal nuchal translucency thickness, free beta-human chorionic gonadotropin and pregnancy-associated plasma protein-A. Ultrasound Obstet Gynecol 2008; 31: 618-624

2 Nicolaides $K H$. A model for a new pyramid of prenatal care based on the 11 to 13 weeks' assessment. Prenat Diagn 2011; 31: 3-6

3 Morgan S, Delbarre A, Ward P. Impact of introducing a national policy for prenatal Down syndrome screening on the diagnostic invasive procedure rate in England. Ultrasound Obstet Gynecol 2013; 41: 526-529

4 Ekelund CK, Jørgensen FS, Petersen OB et al.; Danish Fetal Medicine Research Group. Impact of a new national screening policy for Down's syndrome in Denmark: population based cohort study. BMJ 2008; 337: a2547

5 Kagan KO, Eiben B, Kozlowski P. Kombiniertes Ersttrimesterscreening und zellfreie fetale DNA - „Next Generation Screening“. Ultraschall Med 2014; 35: 229-236

6 Kagan KO, Hoopmann M, Kozlowski P. Assessment of foetal DNA in maternal blood - a useful tool in the hands of prenatal specialists. Geburtsh Frauenheilk 2012; 72: 998-1003

7 Gil MM, Akolekar R, Quezada MS et al. Analysis of cell-free DNA in maternal blood in screening for aneuploidies: meta-analysis. Fetal Diagn Ther 2014; 35: 156-173
8 Statistisches Bundesamt. GeburtenMutterBiologischesAlter.html; Online: https://www.destatis.de/DE/ZahlenFakten/GesellschaftStaat/ Bevoelkerung/Geburten/Tabellen/GeburtenMutterBiologischesAlter. html; Stand: 25.11.2013

9 Cuckle HS, Wald NJ, Thompson SG. Estimating a woman's risk of having a pregnancy associated with Down's syndrome using her age and serum alpha-fetoprotein level. Br J Obstet Gynaecol 1987; 94: 387-402

10 Snijders RJ, Sundberg K, Holzgreve W et al. Maternal age- and gestationspecific risk for trisomy 21. Ultrasound Obstet Gynecol 1999; 13: 167170

11 Willems PJ, Dierickx H, Vandenakker E et al. The first 3,000 Non-Invasive Prenatal Tests (NIPT) with the Harmony test in Belgium and the Netherlands. Facts Views Vis Obgyn 2014; 6: 7-12

12 Cuckle H, Benn P, Pergament E. Maternal cfDNA screening for Down syndrome - a cost sensitivity analysis. Prenat Diagn 2013; 33: 636-642

13 Morris S, Karlsen S, Chung $N$ et al. Model-based analysis of costs and outcomes of non-invasive prenatal testing for Down's syndrome using cell free fetal DNA in the UK National Health Service. PLoS ONE 2014; 9: e93559

14 Beulen L,Grutters JP, Faas BH et al. The consequences of implementing non-invasive prenatal testing in Dutch national health care: a cost-effectiveness analysis. Eur J Obstet Gynecol 2014; 182: 53-61

15 Song K, Musci TJ, Caughey AB. Clinical utility and cost of non-invasive prenatal testing with cfDNA analysis in high-risk women based on a US population. J Matern Fetal Neonatal Med 2013; 26: 1180-1185

16 Lüthgens $K$, Abele $H$, Alkier $R$ et al. [Cross-validation of the first trimester screening algorithm of the FMF London on 38,700 pregnancies in Germany]. Ultraschall Med 2011; 32: 367-372

17 Petersen OB, Vogel I, Ekelund C et al.; the Danish Fetal Medicine Study Group; the Danish Clinical Genetics Study Group. Potential diagnostic consequences of applying non-invasive prenatal testing: populationbased study from a country with existing first-trimester screening. Ultrasound Obstet Gynecol 2014; 43: 265-271

18 Kagan KO, Hoopmann M, Hammer Ret al. Screening auf Chromosomenstörungen mittels Ersttrimester-Screening und non-invasive prenatal Testing. Ultraschall Med 2015; 36: 40-46 